\title{
Effect of Infill Percentage on Properties of FDM Printed GPLA/PETGs
}

\author{
A.V. Sridhar, D. Vamsi Teja, K.V.V.N.R.Chandra Mouli, Balla Srinivasa Prasad, Padmaja
} Anipey

\begin{abstract}
Additive Manufacturing termed by ASTM standard referred to in short as, the technology of fabricating a model based on creating a three-dimensional Computer-Aided Design structure. In the context of developing a product from digital data directly, widely involved various technologies. Amongst them, one being Fused Deposition Modelling (FDM) which supervises the principle of AM, is widely known for developing a polymer-constructed sturdiest range of materials or parts are having operative mechanical properties. Even though, the main problem exaggerates that, the quality of the output still denies due to which void parts are created from bubbles trapped leading to failure of parts under mechanical stresses. Since with $15 \%$ infill, stronger parts are estimated and their mechanical properties are studied. Since the work signifies the influence of $15 \%$ infill on mechanical properties in estimating stronger products by layered addition process. The experimental methodology is based on structural infill parameters determining goal in achieving and studying material mechanical properties.
\end{abstract}

Keywords: Additive Manufacturing; fused deposition modelling; tensile properties; PLA Blend; Infill percentage; $3 D$ Printing.

\section{INTRODUCTION}

Additive manufacturing is evolved first in the 1990s, by adding layer by layer of materials in stacks forming a three-dimensional model or part processes like 3D printing. The 3D printing process asylums huge processing techniques altogether developed by Computer-Aided Design (CAD) Model with a wide variety of forms of materials (powder and liquid molecules) combined. The advantages of this 3D printing techniques originated in producing very complex geometrical shapes from digital data or a .STL file format. The history of 3D printing originated from Woodblock printing (Year 2000), Movable type (1040), Printing press (c. 1440), Etching (c. 1515), Mezzotint (1642), Aquatint (1772), Lithography (1796), Chromolithography (1837), Rotary press (1843),Inkjet printing (1860),Hectograph (1860),Offset

Revised Manuscript Received on December 30, 2019.

* Correspondence Author

A.V. Sridhar, Ph.D. scholar, Dept.of Mechanical Engg, GIT, GITAM, Visakhapatnam, India. Email: situutis.situutis@gmail.com

D. Vamsi Teja, UG student, Dept.of Mechanical Engg, GIT, GITAM, Visakhapatnam, India. Email: vteja97@gmail.com

K.V.V.N.R.Chandra Mouli, Ph.D. scholar, Dept.of Mechanical Engg, GIT, GITAM, Visakhapatnam, India.

Email: chandramouli.karaka@gmail.com

Balla Srinivasa Prasad*, Associate Professor, Dept. of Mechanical Engg, GIT, GITAM, Visakhapatnam, India. Email: bsp.prasad@gmail.com

Padmaja Anipey, Assistant Professor, Dept. of Mechanical Engg, Vizag Institute of Technology, Visakhapatnam, India.

Email: padmaja.anipey@gmail.com

(C) The Authors. Published by Blue Eyes Intelligence Engineering and Sciences Publication (BEIESP). This is an open access article under the CC BY-NC-ND license (http://creativecommons.org/licenses/by-nc-nd/4.0/) printing (1875), Hot metal typesetting (1884), Mimeograph (1886), Photostat and recti graph (1907), Screen printing (1911), Spirit duplicator (1923), Dot-matrix printing (1925), Xerography (1938), Spark printing (1940), Phototypesetting (1949), Dye-sublimation (1957), Laser printing (1969), Thermal printing (c. 1972), Solid ink printing (1986), 3D printing (1986) and later in 1990's it's enormously been adopted till date. Important techniques one among the Additive Manufacturing is the Fused Deposition Modeling (FDM), patented by Stratasys (USA, 1992). FDM is an affordable widely used technique in developing prototypes or parts with polylactide (PLA) or Acrylonitrile Butadiene Styrene (ABS). These materials are heated above their melting point and deposited layer by layer on a substrate through numerically controlled (NC) moving nozzles based on the CAD model created. The evolving technology of manufacturing process it is important to study the mechanical properties of the parts being manufactured and their strength [1]. This is because it is prior, to increase the strength of the parts or products developed comparable to the conventionally developed parts. Various characteristics like thermal and mechanical strength are also been into studies further leading to improvements in the parts or products to be developed [2]. The additives in the layered composition had gone investigations [3] with respects to the pressure and temperature ranging conditions [4]. It is evident that researched been carried out on molecular affinity of the cell along with mechanical properties [5] by additive manufacturing techniques. The tensile strengths of these molecular level characteristics are also effective in the layering process resulted in stronger interaction among intermolecular states. the strength of the additive manufactured parts is studied along with biodegradable interference [6] improving the PLA crystallinity [7] challenging the defects of the PLA materials. By reinforcing Glass into PLA composites investigations prove the zeal to improved mechanical and thermal properties of the PLA along with the foaming ability [8]. Since FDM has low surface quality, efforts have been made to increase the quality by the processing of laser polishing and their effects on the mechanical properties [9]. Another study involved that; polydopamine coated recycled PLA materials to be reused involving mechanical behaviour so as economize the use of PLA [10]. Including CNT along with PLA shows a significant effect on crystallization MRF and Melting rate [11] and decreased percentage of density rate [12] is observed along with recycled PLA [13] used through the process of FDM additive manufacturing technique. So the present work is focused on studying the mechanical properties of different fill percentage accordingly as well as cost-efficient. 


\section{METHODOLOGY}

Figure 1 gives the various stages of the present work. This is starts with preparation of 3D CAD model of the specimen and followed by FDM based 3D printing as well as specimen preparation by Laser cutting for subsequent testing on universal testing machine.

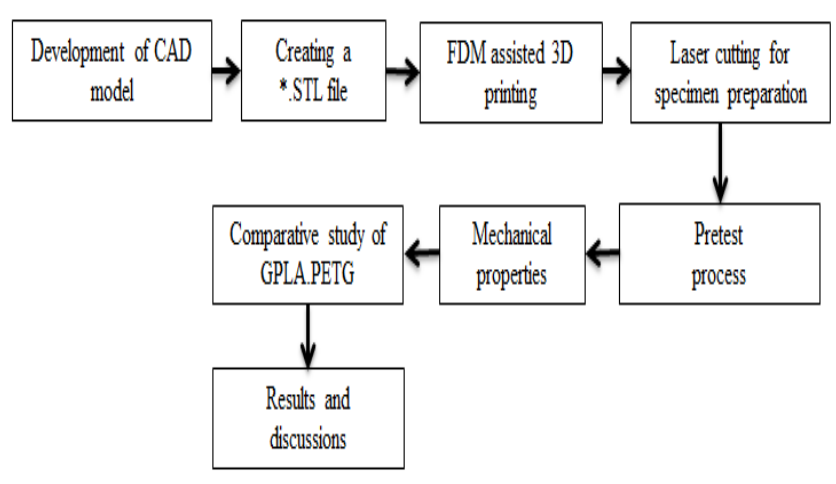

Figure 1 Schematic overview of the methodology

\section{PREPARATION OF CAD MODEL}

The CAD model was prepared in Solid Works 2013 version as per required dimensions of the specimen as shown in the figure-2(b) which is $100 \mathrm{mmX} 50 \mathrm{mmX} 5 \mathrm{~mm}$. The created model then converted into STL format which suitable post-processed during the $3 \mathrm{D}$ printing process. The specimens with required dimensions are then developed in a single jet PRAMAAN 300 3D printer which is as shown in figure 2(a) which can build part up to maximum volumetric dimension having 300mmx300mmx300mm. The high-resolution part is developed ranging from $80-800$ microns suitable for the structural imprints of infill $15 \%$ during the layered by layer deposition process with Honeyco polylactide structural. The GPLA and PETG are developed having bed temperature withstanding from $60-80 \mathrm{oC}$ and its extruder temperature of $190-230 \mathrm{oC}$ and the preceding having the lowest bed temperature of $55-70 \mathrm{oC}$ and an extruder temperature of $210-230 \mathrm{oC}$. The developing of the specimen process advantaged in accordance with the material layer height, speed and density of fill pre-set. The developed specimen is dimensioned to $100 \mathrm{mmX} 12 \mathrm{mmX} 5 \mathrm{~mm}$ as shown in figure 3 using the laser cutting process.

\subsection{Specimen printing by using Fused deposition modelling}

There are a few unique strategies for 3D printing; however the most broadly utilized is a procedure known as Combined Affidavit Displaying (FDM). FDM printers utilize a thermoplastic fiber, which is warmed to its liquefying point and after that expelled, layer by layer, to make a three-dimensional article. The innovation behind FDM was designed during the 1980s by Scott Crump, prime supporter and executive of Stratasys Ltd., a main maker of 3D printers. Other 3D printing associations have since received comparative advances under various names. The Brooklyn-based organization MakerBot (presently possessed by Stratasys), was established on an about indistinguishable innovation known as Combined Fiber Manufacture (FFF). Products or parts fundamentally designed possibly as a (Computer aided design) CAD as file. Before an article can be printed, its computer aided design record must be changed over to an organization that a 3D printer can comprehend for the most part. STL group. FDM printers utilize two sorts of materials, a demonstrating material, which comprises the completed item, and a help material, moves along the platform supporting the part being printed. During printing, these materials show up as plastic strings, or filaments, which are extricated up from a twist and supported through a spout which dissolves the fibers and expels them onto a base, some of the time called it as a base. Both the spout and the base are moved in the directions of $\mathrm{X}, \mathrm{Y}$ and $\mathrm{Z}$ integrated with PC during printing. In a run of the mill FDM framework, the expulsion spout moves over the assemble stage on a level plane and vertically, "drawing" a cross-segment of a part or product onto the stage. This slender layer of plastic cools and solidifies, quickly official to the layer underneath it. When a layer is finished, the base is brought down - generally by around one-sixteenth of an inch - to account for the following layer of plastic. Printing time relies upon the size of the item being fabricated. Little articles - only a couple of cubic inches - and tall, flimsy items print rapidly, while bigger, all the more geometrically complex items take more time to print. Contrasted with other 3D printing strategies, for example, stereolithography (SLA) or specific laser sintering (SLS), FDM is a genuinely moderate procedure. When an article falls off the FDM printer, its help materials are evacuated either by absorbing the item a water and cleanser arrangement or, on account of thermoplastic backings, snapping the help material off manually. Items may likewise be sanded, processed, painted or plated to improve their capacity and appearance. FDM is prevalent with organizations in an assortment of ventures, from car (BMW, Hyundai, and Lamborghini) to shopper products fabricating (Dark and Decker, Dial, Settle). These organizations use FDM all through their item improvement, prototyping and assembling forms. Thermoplastics can suffer warmth, synthetic substances and mechanical pressure, which make them a perfect material for printing models that must withstand testing. Furthermore, in light of the fact that FDM can print exceptionally point by point questions, it's additionally normally utilized by engineers that need to test parts for fit and structure. FDM is additionally used to deliver end-use parts - especially little, nitty gritty parts and concentrated assembling apparatuses.

\subsubsection{Polyethylene Terephthalate Glycol (PETG)}

Polyethylene Terephthalate Glycol (PETG) is a water clear material and intended to be exceptionally 'simple to use' in a scope of uses which is a thermoplastic polymer made through the copolymerization of PET and ethylene glycol. With regards to creating adaptable and solid articles, PETG fiber is picking up fame among fiber makers and the 3D printing network. Being a copolymer, Polyethylene Terephthalate Glycol's substance equation is (C10H8O4)n and its properties incorporate being straightforward with a serious shine surface. It has a high effect obstruction which is like polycarbonate and it's likewise extraordinarily bendable. PETG has brilliant substance obstruction, is effectively thermo formable and is additionally equipped for lessening sound transmissions while likewise being sterile and recyclable.

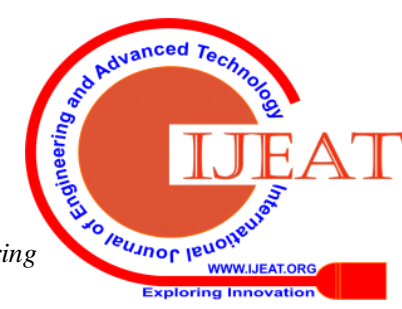


Polyethylene Terephthalate Glycol can be utilized in an assortment of uses including for restorative and nourishment purposes, electronic gadgets, covers and even has the notoriety of joining the usefulness of ABS (more grounded, temperature safe, progressively tough) and unwavering quality of PLA (simple to print) in one material.

\subsubsection{Glass PLA}

Glass Filled PLA 3D printer fibre is a first-of-its-sort designing evaluation fibre that can be utilized on any machine equipped for printing standard PLA. Strands of GPLA offers comparable advantages of standard PLA, for example, a low twist, low scent, and no unique extruder or warmed bed required. In any case, the intensity of its composite make-up enables it to be more grounded, harder and progressively adaptable. In contrast with parts 3D imprinted in standard PLA, Glass Filled PLA is 40\% more grounded than PLA at $57 \mathrm{MPa}$ of max elasticity, 30\% harder than PLA with $34 \mathrm{~J} / \mathrm{m}$ of Effect Durability and $70 \%$ more adaptable than PLA. Glass Filled PLA is a push to progress designed and functional utilizes $3 \mathrm{D}$ printed parts and segments, yet in addition to just idea to clients of PLA a product faraway improved. The properties of the specimen materials are as shown in Table 1.

Table 1 Material properties and process conditions:

\begin{tabular}{|c|r|r|}
\hline PROPERTIES & Glass PLA & PETG \\
\hline Molecular Formula & $\left(\mathrm{C}_{3} \mathrm{H}_{4} \mathrm{O}_{2}\right) \mathrm{n}$ & $\left(\mathrm{C}_{10} \mathrm{H}_{8} \mathrm{O}_{4}\right)_{\mathrm{n}}$ \\
\hline Melting Point & $175^{\circ} \mathrm{C}$ & $250^{\circ} \mathrm{C}$ \\
\hline Density & 1.23 to $1.25 \mathrm{~g} / \mathrm{cm}^{3}$ & $1.27 \mathrm{~g} / \mathrm{cm}^{3}$ \\
\hline Elongation at Break & $3.8 \%$ & $18 \%$ \\
\hline Extrusion Temperature & $190-220^{\circ} \mathrm{C}$ & $220-245^{\circ} \mathrm{C}$ \\
\hline Transparency & Translucent & Translucent \\
\hline
\end{tabular}

\section{EXPERIMENTAL INVESTIGATION}

The experimental procedure is carried out in a sequential process using FDM technique from developing a CAD model to the preparation of the specimen and testing.

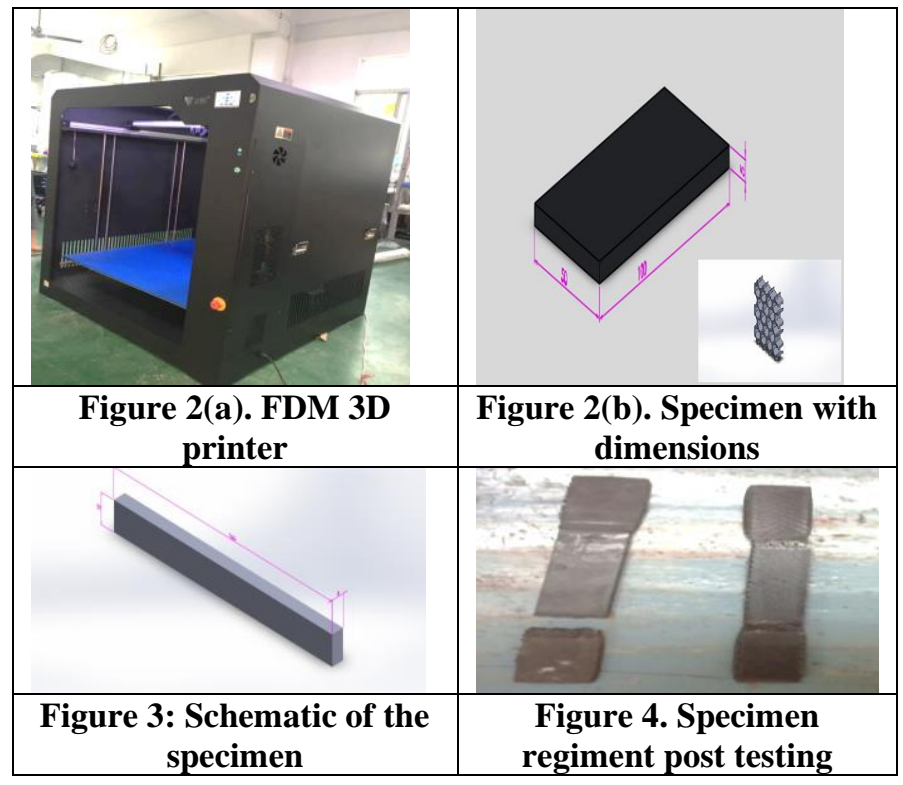

The then prepared samples are then tested for their mechanical properties of tensile, bending and flexure as shown in figure 4. The experimentation process has undergone tensile of mechanical strength for the developed samples using INSTRON testing machine to compare the mechanical properties for the mean taking each of the samples. Various properties are identified by a defined set of axes for overall test samples concerning the dimensional geometry considered.

\subsection{Tensile Investigation:}

The standard ductile tests are led on INSTRON 8801 according to ASTM D3039-07 principles test technique which decides the in-plane malleable properties of glass epoxy composites with or without particulate filler. The element of the example is $100 \mathrm{~mm} \times 12 \mathrm{~mm} \times 5 \mathrm{~mm}$ with a fixed measure length of $100 \mathrm{~mm}$. Tests are directed for the samples at typical room temperature $\left(27^{\circ} \mathrm{C}\right)$ and semi static strain-pace of $10 \mathrm{E}-4 / \mathrm{s}$ with three samples are tried having mean strength as shown in figure 5(a) and 5(b).

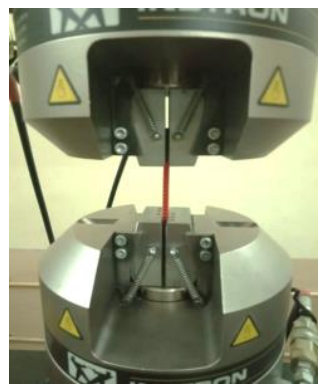

Figure 5(a). Tensile test on

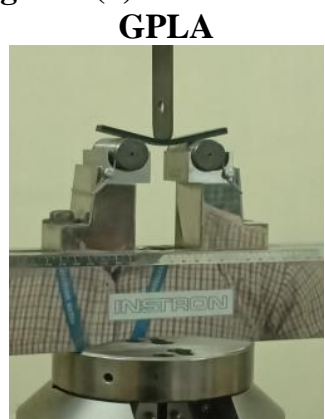

Figure 6(a). 3Point

bending test - GLPA

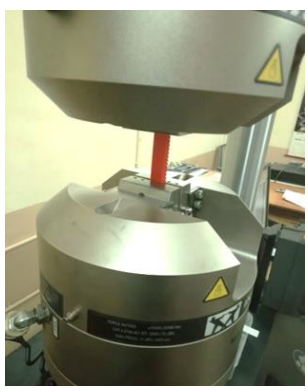

Figure 5(b). Tensile test on

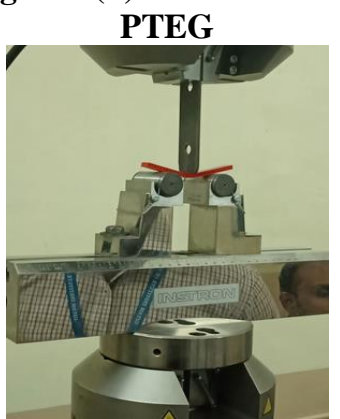

Figure 6(b). 3 Point bending test - PETG

\subsection{Three point bending}

Three-point twisting test more often than not gives esteems to the flexural test, flexural strain, modulus of versatility in bowing and the flexural stress-strain reprimand the material. The technique for testing includes generally a predefined content installation on an UTM which is as shown in Fig. 6(a) and Fig. 6(b). The samples are set on two supporting pins at a specific distance separated. The flexural quality is the most extreme tractable pressure that it can withstand during bowing before arriving at the limit. The three-point twist test is led on GPLA and PTEG tests utilizing a testing machine INSTRON 8801 according to ASTM D790-10 standard test technique as shown in Fig. 6(a) and 6(b). The specimen with a range of $50 \mathrm{~mm}$ length and a consistent crosshead speed of $1.5 \mathrm{~mm} / \mathrm{min}$ is kept up. For both flexural quality and ILSS, the mean is found.

\subsection{Flexure strength}

The flexural strength of the rectangular composite specimen under a load in a three-point bending setup:

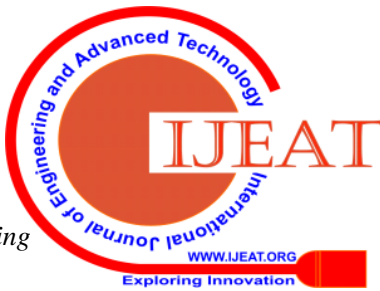


$\sigma=\frac{3 F L}{2 b d^{2}}$

Where $\sigma$ is flexural strength, F-is load (force, $\mathrm{N}$ ) at fracture, $\mathrm{L}$ is the length of the sample (mm), b is width of specimen $(\mathrm{mm})$ and $\mathrm{d}$ is the thickness.

Strain, $\boldsymbol{\varepsilon}=\delta \mathrm{L} / \mathrm{L}$

Where, $\varepsilon=$ strain;

\section{$\delta \mathrm{L}=$ Change in original Length;}

\section{$\mathrm{L}=$ Original length;}

With infill having $15 \%$ the strain values are observed to be increase as shown in the figure 7 and figure 8. Flexure properties are also found to be improved as shown in figures 12 and 13 where a higher value of flexure stress is found with GPLA than PETG.

\section{RESULTS AND DISCUSSION}

\subsection{Tensile properties}

ASTM standards have been thoroughly followed while testing the specimen for its tensile properties. Most of the papers focus on the yield strength, ultimate tensile strength, elongation at $2 \%$ strain etc.

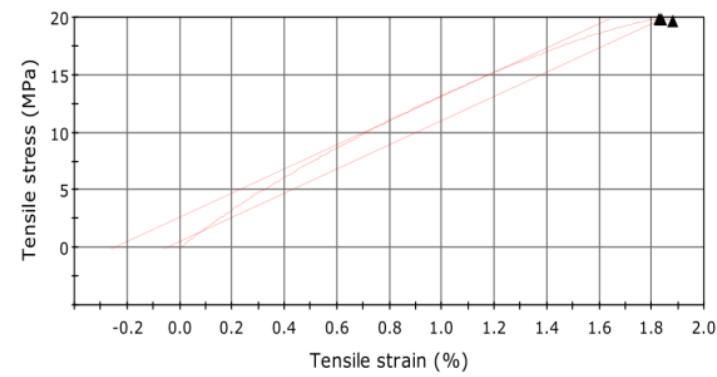

Figure 7: Tensile Strength of GPLA

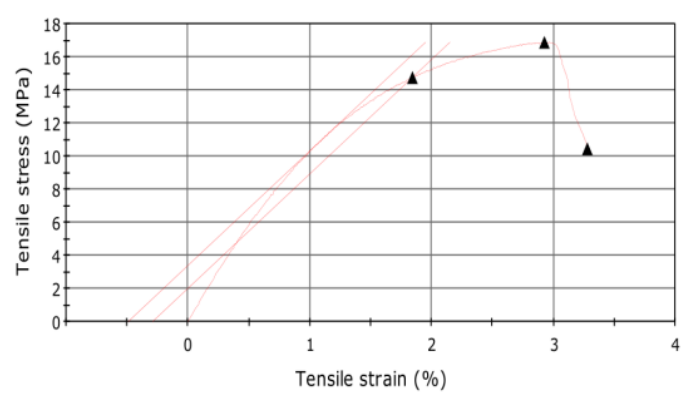

Figure 8: Tensile Strength of PGET

However, we focused our experimentation on finding out the strength per weight ratio of the component. The tensile properties were observed for different materials such as GPLA and PTEG are manufactured using Fused Deposition Modelling (FDM) or Fused Filament Fabrication (FFF). The tensile stress to strain graph obtained for GPLA is shown in figure 7 , observed the maximum stress at 20MPa and from the figure 8 , the tensile strength of the Specimen PETG shows that the maximum stress induced is at $17 \mathrm{MPa}$. With increase in the infill percentage of the GPLA, tensile and flexure properties are found to be improved [14]. From the 3 -point bending test significant improvement in flexure properties are identified in GPLA when compared to PTEG.

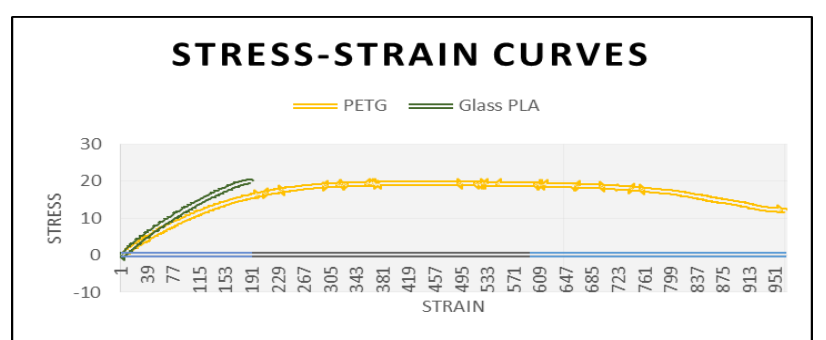

Figure 9: Comparative Graphical representation of Stress versus strain

When comparing the tensile properties of GPLA and PETG from figure 9, it is evident that the GPLA gain higher tensile properties than that of PETG. As the maximum stress of GPLA is observed at 20Mpa when compared to that of PETG which is at $17 \mathrm{Mpa}$. Since GPLA will be inducing higher property of strength at maximum load-bearing properties.

\subsection{Young's modulus}

The Young's modulus for the specimen of GPLA and PETG as shown in figure 10. It is evident from the graph that Young's modulus of Glass PLA is maximum when compared to other materials which were tested.

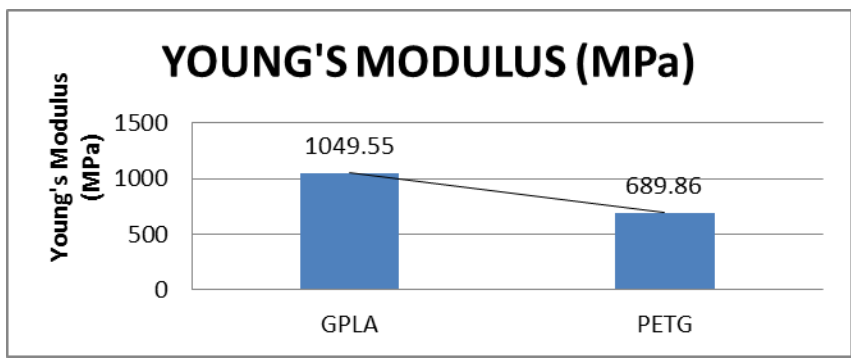

Figure 10: Graphical representation of Young's Modulus of GPLA and PETG

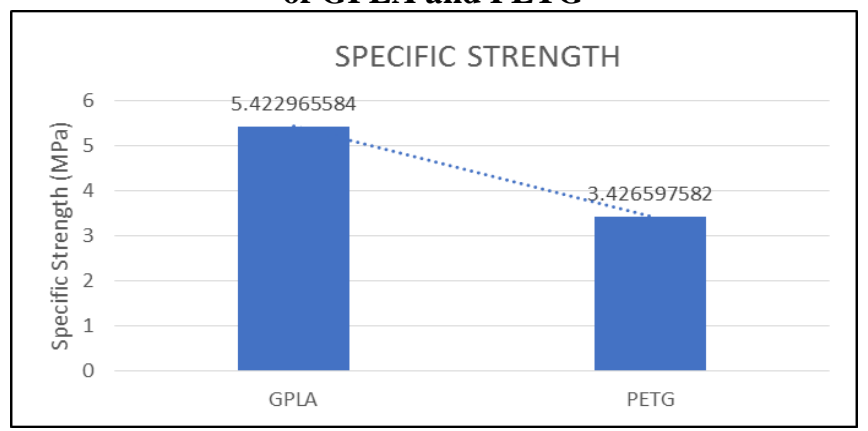

Figure 11: Specific strength of GPLA and PETG

This is because Glass PLA is a composite of Glass fibres reinforced with PLA filament making PLA stronger by almost 1.4 times that of PLA. Also, ease of printing was observed in the case of Glass PLA. From the figure 10, is it clear that as the infill percentage increased and corresponding specific strength amassed in GPLA as well as enhanced modulus value [15]. Similarly, from the figure 11, the specific strength of GPLA is higher when compared to PETG where both specific strength and modulus is observed to be enhanced owing to the effect of Infill percentage.

5.3 Specific strength of GPLA and PETG

Furthermore, when comparing the specific strength among the materials, Glass PLA had the highest specific strength. Its specific strength is $5.44 \mathrm{MPa} / \mathrm{gm}$ and PETG has the least specific strength of $3.85 \mathrm{MPa} / \mathrm{gm}$ only.

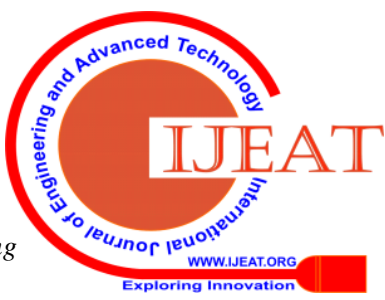


Even though PETG had the highest Ultimate Tensile Strength of $19.34 \mathrm{MPa}$, it was compensated by its weight was $5.79 \mathrm{gm}$. Similarly, the specific strength of the GPLA is found to be $5.422 \mathrm{MPa}$ and PETG to be $3.42 \mathrm{MPa}$ as shown in figure 11. From the observation it is found that the specific strength of GPLA with 15\% infill is higher to that of PTEG resulting in enhanced properties of GPLA and PETG [16].

\subsection{Flexure properties}

Three point bending Tests or flexural tests were conducted on the printed three specimens of each material, which means 9 samples were tested for 3-point bending. Multiple bending assessments were carried out to observe the change in the flexural values in the same structure. This shows the anisotropy in the 3-D printed structure. The materials tested for flexural strength are PETG and Glass PLA.

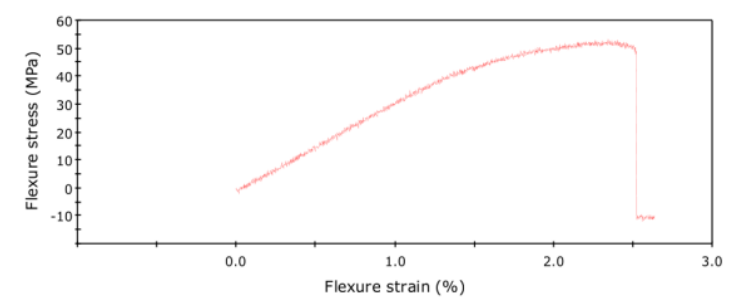

Figure 12: Flexure Stress versus strain of GPLA

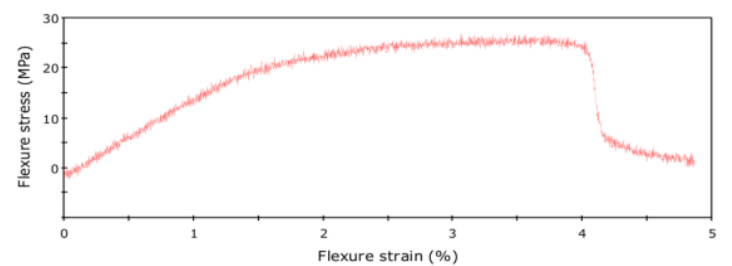

Figure 13: Flexure Stress versus strain of PETG

Flexural Strength of GPLA is observed that the flexure strength is maximum at 50MPa stress for GPLA which is as shown in the figure 12 . The flexure is also found for the PETG as shown in the Figure 13. By comparing the graphs of all the materials which have been tested for flexural strengths, we can see that within the same material, the values are different even when taken from different sides. A drastic change in the properties was observed in the case of Glass PLA where the difference of $+22 \mathrm{MPa}$ and $-23 \mathrm{MPa}$ can be observed as shown in figure 12. On the other hand, from Figure 13 it is observed that PETG has a miniature deviation compared to GPLA. That difference can almost be neglected while characterizing these polymers. A comparable analysis of GPLA and PETG proving that GPLA that highest Flexure strength when compared to PETG which had a maximum of 23Mpa of stress than that of GPLA which had maximum stress at 50MPa. This shows that GPLA had greater Flexure strength when compared to PETG.

\section{CONCLUSIONS}

The main aim of the current investigation is in finding out the enhanced material properties with $15 \%$ infill estimating increased strength with comparing different 3D printed materials. The methodology which is based on the comparative study of strength among GPLA and PETG in obtaining the enhanced properties gave a route for developing more economical materials installing infill percentage. It is observed that the materials with infill in GPLA had higher withstanding properties upon external forces acting than infilled PETG manufactured by using FDM layer by the layer deposition technique. The results proved that GPLA with 15\% infill has higher mechanical strength when compared to that of PETG with $15 \%$ infill. From the results obtained, proving that embedding infill, gave enhanced mechanical strength to the existing materials maintaining increased strength with the lessened weight leading to a futuristic solution.

Study signifies that:

- Tensile properties of the GPLA had been improved with infill that PETG.

- Overall Specific strength of the FDM manufactured GPLA part with infill resulted in enhanced properties than PETG.

- Observations show that PETG with $15 \%$ infill also shows improved strength to that of without infill [17].

- Comparatively Flexure stress to strain ratio among the samples, observations clearly show that GPLA had higher Flexure strength vice versa increased specific strength is found.

The observations from the methodology defined from the experimental investigation carried out proved those mechanical properties GPLA is enhanced when compared to PETG.

\section{REFERENCES}

1. Carlier, E., Marquette, S., Peerboom, C., Denis, L., Benali, S., Raquez, J.M., Amighi, K. and Goole, J., "Investigation of the parameters used in fused deposition modeling of poly (lactic acid) to optimize 3D printing sessions," in International journal of pharmaceutics, 565, 2019, pp.367-377.

2. Abdelwahab, M.A., Flynn, A., Chiou, B.S., Imam, S., Orts, W. and Chiellini, E., "Thermal, mechanical and morphological characterization of plasticized PLA-PHB blends," in Polymer Degradation and Stability, 97(9), 2012, pp.1822-1828.

3. Uzunlar, E. and Kohl, P.A., "Thermal and photocatalytic stability enhancement mechanism of poly (propylene carbonate) due to $\mathrm{Cu}(\mathrm{I})$ impurities," in Polymer degradation and stability, 97(9), 2012, pp.1829-1837.

4. Zhang, H.H., Xiang, H.W., Yang, Y., Xu, Y.Y. and Li, Y.W. "Depolymerization of poly (trimethylene terephthalate) in supercritical methanol," in Journal of applied polymer science, 92(4), 2004, pp.2363-2368.

5. Wei, Q., Cai, X., Guo, Y., Wang, G., Guo, Y., Lei, M., Song, Y., Yingfeng, Z. and Wang, Y., "Atomic-scale and experimental investigation on the micro-structures and mechanical properties of PLA blending with CMC for additive manufacturing," in Materials \& Design, 183, 2019, p.108158.

6. Cai, H., Li, X., Chu, C., Xue, F., Guo, C., Dong, Q. and Bai, J., “Insight into the effect of interface on the mechanical properties of Mg/PLA composite plates," in Composites Science and Technology, 183, 2019, p.107801.

7. Simmons, H., Tiwary, P., Colwell, J.E. and Kontopoulou, M., "Improvements in the crystallinity and mechanical properties of PLA by nucleation and annealing," in Polymer Degradation and Stability, 2019.

8. Wang, G., Zhang, D., Wan, G., Li, B. and Zhao, G., "Glass fiber reinforced PLA composite with enhanced mechanical properties, thermal behavior, and foaming ability," in Polymer, 181, 2019, p.121803.

9. Chen, L. and Zhang, X., "Modification the surface quality and mechanical properties by laser polishing of Al/PLA part manufactured by fused deposition modeling," in Applied Surface Science, 2019.

10. Zhao, X.G., Hwang, K.J., Lee, D., Kim, T. and Kim, N., "Enhanced mechanical properties of self-polymerized polydopamine-coated recycled PLA filament used in 3D printing," in Applied Surface Science, 2018, 441, pp.381-387.

Published By:

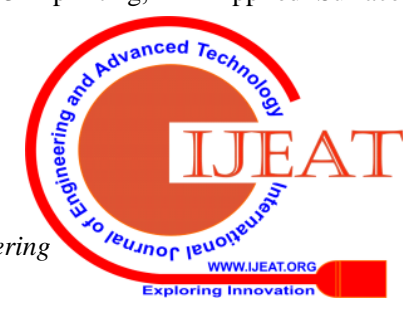


11. Yang, L., Li, S., Zhou, X., Liu, J., Li, Y., Yang, M., Yuan, Q. and Zhang, W., "Effects of carbon nanotube on the thermal, mechanical, and electrical properties of PLA/CNT printed parts in the FDM process," in Synthetic Metals, 253, 2019, pp.122-130.

12. Lay, M., Thajudin, N.L.N., Hamid, Z.A.A., Rusli, A., Abdullah, M.K. and Shuib, R.K., "Comparison of physical and mechanical properties of PLA, ABS and nylon 6 fabricated using fused deposition modeling and injection molding," in Composites Part B: Engineering, 176, 2019, p.107341.

13. Lanzotti, A., Martorelli, M., Maietta, S., Gerbino, S., Penta, F. and Gloria, A., "A comparison between mechanical properties of specimens 3D printed with virgin and recycled PLA," in Procedia CIRP, 79, 2019, pp.143-146.

14. Alvarez, C., Kenny, L., Lagos, C., Rodrigo, F. and Aizpun, M., "Investigating the influence of infill percentage on the mechanical properties of fused deposition modelled ABS parts," in Ingeniería e Investigación, 36(3), 2016, pp.110-116.

15. Qattawi, A., Alrawi, B. and Guzman, A., "Experimental optimization of fused deposition modelling processing parameters: a design-for-manufacturing approach,” in Procedia Manufacturing, 10, 2017, pp.791-803.

16. Chai, X., Chai, H., Wang, X., Yang, J., Li, J., Zhao, Y., Cai, W., Tao, T. and Xiang, X., "Fused deposition modeling (FDM) 3D printed tablets for intragastric floating delivery of domperidone," in Scientific reports, 7(1), 2017, p.2829.

17. Fernandez-Vicente, M., Calle, W., Ferrandiz, S. and Conejero, A. "Effect of infill parameters on tensile mechanical behavior in desktop 3D printing," in 3D printing and additive manufacturing, 3(3), 2016, pp.183-192.

\section{AUTHORS PROFILE}

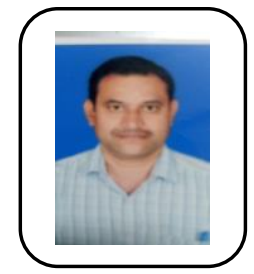

Mr. A V Sridhar, presently working as Assoc. Prof in Mechanical Engineering Department at GIET Engineering College Rajahmundry, India. Presently i am pursuing my part-time Ph.D. at GITAM University, Visakhapatnam in mechanical engineering under the guidance of Dr .Balla Srinivasa Prasad. I have 14 years of Teaching experience and 6 years of industrial experience.

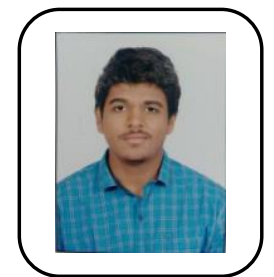

Mr. Vamsi Teja. Dadi is graduated in Mechanical Engineering from GIT, GITAM Deemed to be University, Visakhapatnam, India in 2019. He did his final year project in the field of Additive Manufacturing under the guidance of Dr.Balla Srinivasa Prasad at GITAM. His keen interest lies in Advancement of Manufacturing process and is pursuing his masters in the same field.

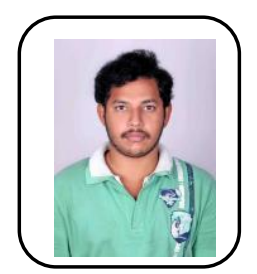

Mr. K.V.V.N.R. Chandra Mouli is a research scholar in GITAM Deemed to be University, Visakhapatnam, India under the guidance of Dr. Balla Srinivasa Prasad. Presently working as an Assistant professor in one of the reputed colleges in mechanical department, affiliated to JNTU Kakinada, India. He done his master's in CAD/CAM from GITAM and graduated from B.Tech.(Mechanical Engg) from JNTU Kakinada. His research interests include Additive Manufacturing and Multi sensor fusion techniques.

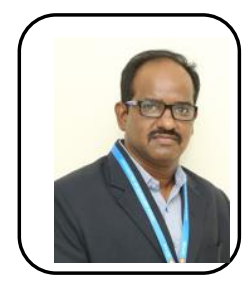

Dr. Balla Srinivasa Prasad presently working as Associate Professor in Mechanical Engineering, GIT, GITAM, Visakhapatnam, India since 2003. He was graduated in B.E (Mechanical Engg) from Andhra University- Visakhapatnam, Master's degree in Production Engineering from S V University, Tirupati. He was awarded Ph.D. from Andhra University in 2010. Dr Balla so far published 30 peer reviewed publications and actively engaged in research in fields of Additive manufacturing, Tool condition monitoring and multi sensor fusion etc.

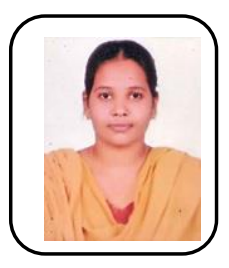

Ms. Padmaja Anipey graduated in B.E. (MPIE) from College of Engineering, GITAM (AU), Visakhapatnam, India. She obtained her Master's degree in HTES from Andhra University, Visakhapatnam. She has more than 6 years of experience for teaching B.Tech students. At present working as Assistant Professor at Vizag Institute of Technology, Visakhapatnam, India. 